\title{
Field Test Program to Develop Comprehensive Design, Operating and Cost Data for Mercury Control Systems on Non-Scrubbed Coal-Fired Boilers
}

\author{
Quarterly Technical Report \\ Reporting Period: July 1, 2001 - September 30, 2001
}

\author{
Principal Authors \\ C. Jean Bustard \\ ADA Environmental Solutions, LLC \\ 8100 SouthPark Way, B-2 \\ Littleton, Colorado 80120
}

Submitted: October 12, 2001

DOE Cooperative Agreement No.: DE-FC26-00NT41005

Report No. 41005R04 


\section{DISCLAIMER}

This technical report was prepared with the support of the U.S. Department of Energy, under Award No. DE-FC26-00NT41005. However, any opinions, findings, conclusions, or recommendations expressed herein are those of the author(s) and do not necessarily reflect the views of the DOE.

This report was prepared as an account of work sponsored by an agency of the United States Government. Neither the United States government nor any agency thereof, nor any of their employees, makes any warranty, express or implied, or assumes any legal liability or responsibility for the accuracy, completeness, or usefulness of any information, apparatus, product, or process disclosed, or represents that its use would not infringe privately owned rights. Reference herein to any specific commercial product, process, or service by trade name trademark, manufacturer, or otherwise does not necessarily constitute or imply its endorsement, recommendation, or favoring by the United States Government or any agency thereof. The views and opinions of authors expressed herein do not necessarily state or reflect those of the United States Government or any agency thereof. 


\section{ABSTRACT}

With the Nation's coal-burning utilities facing the possibility of tighter controls on mercury pollutants, the U.S. Department of Energy is funding projects that could offer power plant operators better ways to reduce these emissions at much lower costs.

Mercury is known to have toxic effects on the nervous system of humans and wildlife. Although it exists only in trace amounts in coal, mercury is released when coal burns and can accumulate on land and in water. In water, bacteria transform the metal into methylmercury, the most hazardous form of the metal. Methylmercury can collect in fish and marine mammals in concentrations hundreds of thousands times higher than the levels in surrounding waters.

One of the goals of DOE is to develop technologies by 2005 that will be capable of cutting mercury emissions 50 to 70 percent at well under one-half of today's costs. ADA Environmental Solutions (ADA-ES) is managing a project to test mercury control technologies at full scale at four different power plants from 2000 - 2003. The ADA-ES project is focused on those power plants that are not equipped with wet flue gas desulfurization systems.

ADA-ES will develop a portable system that will be moved to four different utility power plants for field testing. Each of the plants is equipped with either electrostatic precipitators or fabric filters to remove solid particles from the plant's flue gas.

ADA-ES's technology will inject a dry sorbent, such as fly ash or activated carbon, that removes the mercury and makes it more susceptible to capture by the particulate control devices. A fine water mist may be sprayed into the flue gas to cool its temperature to the range where the dry sorbent is most effective.

PG\&E National Energy Group is providing two test sites that fire bituminous coals and are both equipped with electrostatic precipitators and carbon/ash separation systems. Wisconsin Electric Power Company is providing a third test site that burns Powder River Basin (PRB) coal and has an electrostatic precipitator for particulate control. Alabama Power Company will host a fourth test at its Plant Gaston, which is equipped with a hot-side electrostatic precipitator and a downstream fabric filter.

During the fourth reporting quarter, progress was made on the project in the following areas:

\section{Alabama Power Company Plant Gaston}

- Economic analysis and topical report tasks continued.

- A technical paper on the Plant Gaston work was presented at the MEGA Symposium/AWMA Mercury Specialty Conference. 


\section{Wisconsin Electric Power Company Pleasant Prairie Power Plant}

- Site preparation work was completed for the field testing phases of the project.

- Baseline testing was completed and parametric testing was initiated during the quarter.

- A technical poster paper on the Pleasant Prairie Power Plant work was presented at the MEGA Symposium/AWMA Mercury Specialty Conference.

- The site hosted a tour as part of the Mercury Specialty Conference.

\section{PG\&E NEG Salem Harbor Station}

- Coal and ash samples continued to be tested and analyzed.

- A technical poster paper on the Salem Harbor work was presented at the MEGA Symposium/AWMA Mercury Specialty Conference.

\section{PG\&E NEG Brayton Point Station}

- Coal and ash samples continued to be tested and analyzed.

- $\quad$ Site work began in preparation for testing during 2002.

\section{Technology Transfer}

- Three technical presentations were made at the MEGA Symposium/AWMA Mercury Specialty Conference.

- A technical paper was presented at the $9^{\text {th }}$ Annual Powder River Basin Coal Technical Conference.

- A presentation was made at the Reinhold ESP/Fabric Filter Roundtable meeting.

- A technical paper was presented at the DOE/China Clean Energy Technology Forum, Beijing, China.

- An article on the project appeared in the July 2001 issue of EM.

- An article on the project appeared in the August 162001 issue of the Wall Street Journal. 


\section{TABLE OF CONTENTS}

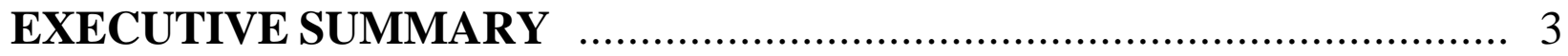

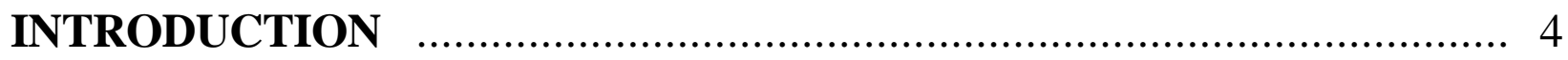

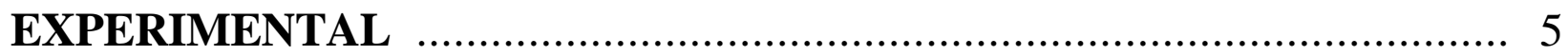

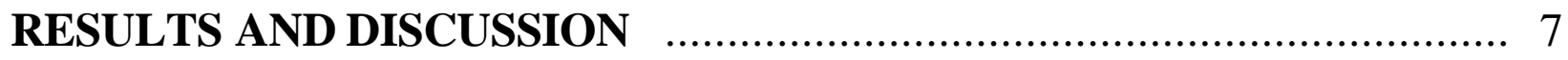

CONCLUSION

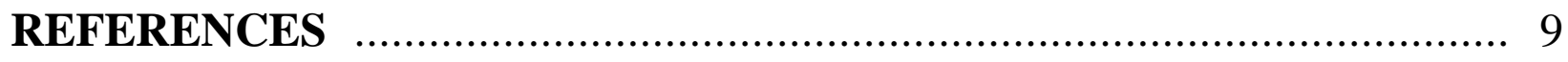

LIST OF ACRONYMS AND ABBREVIATIONS ….......................... 10 


\section{LIST OF GRAPHICAL MATERIALS}

There are no graphical materials included in this report. 


\section{EXECUTIVE SUMMARY}

ADA-ES began work on a Cooperative Agreement with the Department of Energy in October, 2000 to demonstrate full-scale mercury control systems at coal-fired power plants. The project is the next step in the process of obtaining performance and cost data on full-scale utility plants for mercury control systems. Power generating companies that have entered into contracts with ADA-ES are PG\&E National Energy Group, Wisconsin Electric Power Company and Alabama Power Company. During the three-year, $\$ 6.8$ million project, integrated control systems will be installed and tested at four power plants. ADA-ES is responsible for managing the project including engineering, testing, economic analysis, and information dissemination functions.

On December 14, 2000 the Environmental Protection Agency (EPA) announced that it will be developing regulations for reducing emissions of mercury from coal-fired power plants.

Proposed regulations are expected to be released by December, 2003 and the rules are scheduled to be finalized by December, 2004. It is expected that EPA will include the findings from the ADA-ES/DOE project in its analysis for establishing a mercury control regulation. DOE estimates that the cost to control these emissions will be $\$ 2-\$ 5$ billion annually.

The field test phase of the project began at Alabama Power Company's Plant Gaston during the second reporting quarter. Testing at this site was completed in the third reporting quarter. Sorbent screening testing was completed at Wisconsin Electric's Pleasant Prairie Power Plant during the third reporting quarter and equipment was installed at the site during the fourth reporting quarter. Baseline and parametric testing began during the fourth reporting quarter. . Prebaseline testing was done at PG\&E NEG's Brayton Point Station during the third quarter and the site was visited during the fourth quarter to scope out modification that will be needed to install testing equipment. Site prep work began during the fourth quarter to accommodate test equipment. A number of technology transfer activities took place during the fourth reporting quarter including presenting papers on the project at the A\&WMA Specialty Conference on Mercury Emissions: Fate, Effects, and Control and The US EPA/DOE/EPRI Combined Power Plant Air Pollutant Control Symposium: The Mega Symposium. 


\section{INTRODUCTION}

Cooperative Agreement No. DE-FC26-00NT41005 was awarded to ADA-ES to demonstrate mercury control technologies on non-scrubbed coal-fired boilers. Under the contract, ADA-ES will work in partnership with PG\&E National Energy Group, Wisconsin Electric Power Company, Alabama Power, and EPRI to design and engineer systems to maximize effectiveness and minimize costs to curtail mercury emissions from power plant flue gases. Reports estimate that mercury control could cost the industry from $\$ 2$ to $\$ 5$ billion per year. Much of these costs will be associated with power plants that do not have wet scrubbers as part of their air pollution control configurations. The four plants that will be evaluated during the ADA-ES program are typical of this type of application which is found at $75 \%$ of the nearly 1100 units that would be impacted by new regulations.

Detailed topical reports will be prepared for each site that is tested under the program. Quarterly reports will be used to provide project overviews and technology transfer information. 


\section{EXPERIMENTAL}

Field work was conducted on the project during the fourth reporting quarter at Wisconsin Electric'c Pleasant Prairie Power Plant. Site modifications were started at the Brayton Point Station. Detailed results of the testing at each power plant will be provided in separate topical reports.

\section{Technology Transfer}

Technology transfer activities continued during the fourth reporting quarter of the project. Reference citations of the formal presentations are provided below:

Schlager, R., M.D. Durham, C.J. Bustard, R Schlager, C. Martin, S. Johnson and S. Renninger, (2001). "Field Test Program to Develop Comprehensive Design, Operating and Cost Data for Sorbent Based Mercury Control Systems," presented at DOE/China Clean Energy Technology Forum, Beijing, China, August 29-31.

Bustard, C.J., M. Durham, C. Lindsey, T. Starns, K. Baldrey, C. Martin, S. Sjostrom, R. Slye, S. Renninger and L. Monroe (2001). "Full Scale Evaluation of Mercury Control with Sorbent Injection and COHPAC at Alabama Power E.C. Gaston," presented at the A\&WMA Specialty Conference on Mercury Emissions: Fate, Effects, and Control and The US EPA/DOE/EPRI Combined Power Plant Air Pollutant Control Symposium: The Mega Symposium, Chicago, IL, August 20-23. (copy in Attachment B)

Johnson, S., J. Bustard, M. Durham, S. Sjostrom, R. Slye, R. Afonso, C. Senior, A. Sload, M. Kane, D. Bondar, H. Stowe and S. Renninger (2001). "Mercury Measurements at Harbor Units $1 \& 3$," presented at the A\&WMA Specialty Conference on Mercury Emissions: Fate, Effects, and Control and The US EPA/DOE/EPRI Combined Power Plant Air Pollutant Control Symposium: The Mega Symposium, Chicago, IL, August 20-23.

Martin, C., T. Starns, D. Johnson and S. Haythornthwaite (2001). "Full Scale Mercury Control on Pleasant Prairie Unit 2," presented at the A\&WMA Specialty Conference on Mercury Emissions: Fate, Effects, and Control and The US EPA/DOE/EPRI Combined Power Plant Air Pollutant Control Symposium: The Mega Symposium, Chicago, IL, August 20-23.

Schlager, R.J. M. Durham, J. Bustard, C. Lindsey, T. Starns, K. Baldrey, C. Martin, S. Renninger, S. Sjostrom, R. Slye, L. Monroe and R. Chang (2001). "Mercury Control for Coal-Fired Boilers," presented at the $9^{\text {th }}$ Annual Powder River Basin Coal Technical Conference, Gillette, WY, August 15-16.

Bustard, C.J. (2001). "Field Test Program to Develop Comprehensive Design, Operating and Cost Data for Sorbent Based Mercury Control Systems," presented at the Reinhold ESP/FF Roundtable and Exhibition, St. Louis, MO, July 24. 
Durham, M.D., C.J. Bustard, R Schlager, C. Martin, S. Johnson and S. Renninger, (2001).

"Controlling Mercury Emissions from Coal-Fired Utility Boilers: A Field Test," EM, pp. 2733, July. (copy in Attachment B)

There was also an article on the project that appeared in the Wall Street Journal. The reference for this is:

Fialka, J.J. (2001). "Power Drain: The U.S. Energy Crisis. DOE's Mercury Removal Tests a Success but More Work is Needed to Reduce Costs," The Wall Street Journal, p. 16, August 20. (copy in Attachment B) 


\section{RESULTS AND DISCUSSION}

The major effort during the fourth reporting quarter focused on the WEPCO Pleasant Prairie

Power Plant an technology transfer activities. Site work was completed and the field testing phase began at Pleasant Prairie. The testing at the site will be completed during the next

reporting period. Detailed results of the testing at each power plant will be provided in separate topical reports. 


\section{CONCLUSION}

Work began on Cooperative Agreement No. DE-FC26-00NT41005 in October 2000. Initial activities include holding a project kickoff meeting, securing the fourth test site (Alabama Power Company Plant Gaston), and performing various planning and administrative functions. Field testing began during the second reporting period at Plant Gaston, and test planning for the remaining sites began. Test work was completed at the Gaston site during the third reporting period. Site preparations were completed and field testing began at Wisconsin Electric during the fourth reporting period. Technology transfer activities are progressing at a rapid pace. Several new power companies have joined the project team. 


\section{REFERENCES}

None this reporting period. 


\section{LIST OF ACRONYMS AND ABBREVIATIONS}

$\begin{array}{ll}\text { A\&WMA } & \begin{array}{l}\text { Air \& Waste Management } \\ \text { Association }\end{array} \\ \text { DOE } & \begin{array}{l}\text { Department of Energy } \\ \text { EPA }\end{array} \\ & \begin{array}{l}\text { Environmental Protection } \\ \text { Agency }\end{array} \\ \text { ESP } & \text { Electrostatic Precipitator } \\ \text { PRB } & \text { Powder River Basin } \\ \text { WEPCO } & \begin{array}{l}\text { Wisconsin Electric Power } \\ \text { Co. }\end{array}\end{array}$




\title{
ATTACHMENT A
}

\author{
Accomplishments and Status Assessment \\ July 1, 2001 - September 30, 2001
}

- General

TVA has joined the project team during the quarter.

A team meeting was held on the afternoon of 8/20/01 at the Mercury/MEGA conference.

The project is progressing on schedule without any major deviations from plan.

\section{- Alabama Power Company's Plant Gaston}

This facility was the first to be tested in the program. Prebaseline testing was completed in February, 2001 and the parametric test series was performed in March, 2001. The longterm test series was completed during April, 2001. The test facility was decommissioned during May. Economic analysis and topical report were started in June and are continuing. Ontario Hydro test results have been completed. Several questions on coal and ash analysis remain to be resolved.

- WEPCO Pleasant Prairie Power Plant

Sorbent screening testing was completed at Pleasant Prairie in June, 2001. Equipment installations were completed in August, 2001. Equipment check-out was completed in September and Baseline and Parametric testing began during September 2001.

\section{- PG\&E NEG Salem Harbor Station}

Prebaseline measurements were made at Salem Harbor during February. Mercury emissions measurements were made at the station during July 2001 as required by the state of Massachusetts. Additional prebaseline testing, parametric and long-term testing of Salem Harbor is scheduled for Spring, 2002. Ash samples are being analyzed by Microbeam Technologies and results are being evaluated. A test plan was being prepared during September 2001.

\section{- PG\&E NEG Brayton Point Station}

Prebaseline testing was performed at Brayton Point during June 2001. Mercury emissions measurements were made at the station during the summer of 2001 as required by the state of Massachusetts. The site was visited in July 2001 to evaluate the ductwork, port locations, equipment locations and platform needs. Some site preparation work was done during September 2001. Parametric and long-term testing of Brayton Point is scheduled for Fall, 2002.

\section{- Technology Transfer}

A number of technology transfer activities have taken place since the project began in October 2000. More activities are planned for future conferences, symposia and technical publications. Currently, presentations are planned for a meeting of the New England Section of the A\&WMA (October, 2001), the Western Coal Transportation Association meeting (November, 2001), the DOE Clean Coal and Power Conference (November, 2001), the Fifth Electric Utilities Environmental Conference (January, 2002), the ScienTech Mercury Emissions Workshop (January, 2002), and the 2002 A\&WMA Annual Meeting (June, 2002). 


\section{ATTACHMENT B}

\section{Articles and Technical Papers}


August 20, 2001

\section{Power Drain: The U.S. Energy Crisis}

\section{DOE's Mercury-Removal Test Is a Success, But More Work Is Needed to Reduce Costs}

\section{By JOHN J. FIALKA}

Staff Reporter of THE WALL STREET JOURNAL

WASHINGTON -- The government's first test of whether a high percentage of mercury can be removed from the emissions of a coal-fired power plant has been a success, the Department of Energy said, but it concedes the technique is costly.

Airborne emissions of mercury, a poisonous metallic element that can accumulate in the environment, aren't regulated under the Clean Air Act. But the Bush administration wants to add them to the mix in a bill it is pushing to further reduce emissions of sulfur dioxide and nitrogen oxides, and a stiff debate is expected when Congress takes up the bill next month.

Environmentalists argue that mercury must be quickly eliminated from the air, while the utilities industry complains that mitigation costs, which would have to be passed on to ratepayers, could be exorbitant.

In the Energy Department sponsored test, conducted in the spring, technicians injected activatedcarbon powder into the emissions stack of an older, coal-fired plant operated by the Southern Company near Wilsonville, Ala. The carbon dust -- a material used as an air filter in gas masks -then was captured in a "bag house," or large cloth filter, after it rose toward the top of the stack.

The carbon then absorbed mercury that is released as a vapor in the power plant's combustion process. Technicians estimate they succeeded in removing $80 \%$ to $90 \%$ of the mercury in the test, the first of six joint DOE-utilities industry experiments. "We view this with guarded optimism," said Tom Feeley, the DOE official overseeing the tests.

He called the experiments a "brand-new ballgame" for DOE, which previously had done only laboratory tests to capture the elusive metal, which in some forms can pass right through the "scrubbers" that many power plants use to capture other pollutants. More tests are needed, Mr. Feeley said, because different plants using different types of coal are likely to produce widely varying results. Most congressional proposals to reduce mercury levels have called for cuts to start in 2007.

DOE estimates that reducing mercury by $90 \%$ could at least double the emissions-control costs now paid by U.S. utilities, adding from $\$ 5$ billion to $\$ 8$ billion a year to the nation's utility bills. "The consensus of our industry is that would be very expensive," said Michael Rossler, manager of environmental programs for the Edison Electric Institute, which represents most of the nation's power plants. 
"Once we set the level [of regulation], companies are remarkably effective at finding efficient technologies," countered Jason Grumet, who represents a consortium of environmental agencies from Northeastern states. Their tests show mercury levels are rising in fish, which in turn can cause nerve damage in humans who eat them. Children are believed to be the most vulnerable.

Senate Democrats want to bar emissions-trading programs that are used to curb the output of other pollutants from being extended to mercury. Emissions trading aims to use market forces to direct investments in antipollution technology and energy-efficient equipment to the places where they can be most cost-effective. Utilities that lower emissions below designated levels receive excess credits that they can sell to other companies that can't achieve such goals. The result is supposed to be a net reduction of pollutants.

But critics, led by Senate Environment and Public Works Committee Chairman James Jeffords (I., Vt.), fear that an emissions-trading program for mercury would create "hot spots" where the poisonous materials could continue to accumulate if a utility operator were able to buy pollution credits from cleaner plants elsewhere.

Edison's Mr. Rossler complains that limiting the scope of trading would increase costs for companies, which want to find the cheapest ways of reducing overall levels of the three pollutants targeted in the administration's bill.

Michael Durham is an environmental engineer for ADA Environmental Solutions, a subsidiary of Earth Sciences Inc. of Littleton, Colo., which carried out the Wilsonville experiment. He says finding a broad-gauge solution that applies to older power plants is critical because $75 \%$ of coalfired plants in the U.S. are in this category. And 56\% of the nation's electricity comes from burning coal.

"Our goal was to see what level [of removal] we could get without cutting back the power production of the unit," Mr. Durham said. While the results were encouraging, he warned that the industry must find a less-costly material than activated carbon to absorb mercury. "It's going to be expensive," he predicts. 


\title{
Full-Scale Evaluation of Mercury Control with Sorbent Injection and COHPAC at Alabama Power E.C. Gaston
}

\author{
C. Jean Bustard, Michael Durham, Ph.D., Charles Lindsey, Travis Starns, Ken Baldrey, \\ Cameron Martin
}

ADA-ES, LLC, 8100 SouthPark Way, B-2, Littleton, CO 80120

Sharon Sjostrom, Rick Slye

Apogee Scientific, 2875 W. Oxford Ave., Suite 1, Englewood, CO 80110

Scott Renninger

US Department of Energy, National Energy Technology Laboratory, Collins Ferry Road, P.O. Box 880, Morgantown, WV 26507-0880

Larry Monroe, Ph.D.

Southern Company, 600 North $18^{\text {th }}$ St., Birmingham, AL 35203

Presented at A\&WMA Specialty Conference on Mercury Emissions:

Fate, Effects, and Control

and

The US EPA/DOE/EPRI Combined Power Plant Air Pollutant Control Symposium:

The Mega Symposium

Chicago, IL

August $20-23,2001$ 


\begin{abstract}
The overall objective of this project is to determine the cost and impacts of mercury control using sorbent injection into a COHPAC baghouse at Alabama Power's Gaston Unit 3. This test is part of a program funded by the Department of Energy's National Energy Technology Laboratory (NETL) to obtain the necessary information to assess the costs of controlling mercury from coal-fired utility plants that do not have scrubbers for $\mathrm{SO}_{2}$ control. The economics will be developed based on various levels of mercury control.
\end{abstract}

Gaston Unit 3 was chosen for this evaluation because COHPAC represents a cost-effective retrofit option for utilities with electrostatic precipitators (ESPs). COHPAC is an EPRI patented concept that places a high air-to-cloth ratio baghouse downstream of an existing ESP to improve overall particulate collection efficiency. Dry sorbents were injected upstream of COHPAC, downstream of the ESP to obtain performance and operational data and residue hopper ash and carbon samples was collected to evaluate the impact on disposal byproduct reuse. A series of parametric tests were conducted to determine the optimum operating conditions for several levels of mercury control up to $90 \%$ mercury removal. Based on results from these tests, a two-week test with one sorbent and optimized conditions was conducted to assess longer term impacts to COHPAC and auxiliary equipment.

This paper presents preliminary results from the testing in March and April 2001. 


\section{INTRODUCTION}

In December 2000 EPA announced their intent to regulate mercury emissions from the nation's coal-fired power plants. In anticipation of these regulations, a great deal of research has been conducted during the past decade to characterize the emission and control of mercury compounds from the combustion of coal. Much of this research was funded by the Department of Energy, EPA, and EPRI. The results are summarized in the comprehensive AWMA Critical Review Article ${ }^{1}$. As a result of these efforts, the following was determined:

1. Trace concentrations of mercury in flue gas can be measured relatively accurately;

2. Mercury is emitted in a variety of forms;

3. Mercury species vary with fuel source and combustion conditions; and

4. Control of mercury from utility boilers will be both difficult and expensive.

This latter point is one of the most important and dramatic findings from the research conducted to date. Because of the large volumes of gas to be treated, low concentrations of mercury, and presence of difficult to capture species such as elemental mercury, some estimates show that $90 \%$ mercury reduction for utilities could cost the industry as much as $\$ 5$ billion per year ${ }^{1}$. Most of these costs will be borne by power plants that burn low-sulfur coal and do not have wet scrubbers as part of the air pollution equipment.

With regulations rapidly approaching, it is important to concentrate efforts on the most mature retrofit control technologies. Injection of dry sorbents such as powdered activated carbon (PAC) into the flue gas and further collection of the sorbent by ESPs and fabric filters represents the most mature and potentially most cost-effective control technology for power plants. However, all of the work to date has been conducted using bench-scale and pilot experiments. Although these reduced-scale programs provide valuable insight into many important issues, they cannot fully account for impacts of additional control technology on plant-wide equipment.

Therefore, it is necessary to scale-up the technology and perform full-scale field tests to document actual performance levels and determine accurate cost information. Under a DOE/NETL cooperative agreement, ADA-ES is working in partnership with PG\&E National Energy Group (NEG), Wisconsin Electric, a subsidiary of Wisconsin Energy Corp., Alabama Power Company, a subsidiary of Southern Company, EPRI, and Ontario Power Generation on a field evaluation program of sorbent injection upstream of existing particulate control devices for mercury control'. Other organizations participating in this program as team members include EPRI, Apogee Scientific, URS Radian, Energy \& Environmental Strategies, Physical Sciences, Inc., Southern Research Institute, Hamon Research-Cottrell, Environmental Elements Corporation, Norit Americas, and EnviroCare International. 


\section{DESCRIPTION OF OVERALL PROGRAM}

The Department of Energy's National Energy Technology Laboratory (NETL) is the primary funding agency on an industry cost-shared test program to obtain the necessary information to assess the costs of controlling mercury from coal-fired utility plants that do not have scrubbers for $\mathrm{SO}_{2}$ control. The method for mercury control evaluated in this program is the injection of dry sorbents, such as activated carbon, upstream of the existing particulate control device. The economics will be developed based on various levels of mercury control at four different host sites. The four sites, shown below, burn coal and have particulate control equipment that are representative of $75 \%$ of the coal-fired generation.

\begin{tabular}{|l|l|l|}
\hline Test Site & Coal & Particulate Control \\
\hline $\begin{array}{l}\text { PG\&E NEG } \\
\text { Salem Harbor }\end{array}$ & Low S. Bituminous & Cold-Side ESP \\
\hline $\begin{array}{l}\text { PG\&E NEG } \\
\text { Brayton Point }\end{array}$ & Low S. Bituminous & Cold-Side ESP \\
\hline $\begin{array}{l}\text { Wisconsin Electric } \\
\text { Pleasant Prairie }\end{array}$ & PRB & Cold-Side ESP \\
\hline $\begin{array}{l}\text { Alabama Power } \\
\text { Gaston }\end{array}$ & Low S. Bituminous & $\begin{array}{l}\text { Hot-Side ESP } \\
\text { COHPAC FF }\end{array}$ \\
\hline
\end{tabular}

Gaston Unit 3 was chosen as one of the test sites because COHPAC represents a cost-effective retrofit option for utilities with electrostatic precipitators (ESPs). COHPAC is an EPRI patented concept that places a high air-to-cloth ratio baghouse downstream of an existing ESP to improve overall particulate collection efficiency. The advantages of this configuration are:

1. Sorbents are mixed with a small fraction of the ash (nominally $1 \%$ ) which reduces the impact on ash reuse and waste disposal.

2. Pilot plant studies and theory ${ }^{3}$ indicate that compared to ESPs, baghouses require onetenth the sorbent to achieve similar removal efficiencies.

3. Capital costs for COHPAC are less than other options such as replacing the ESP with a baghouse or larger ESP.

In this test, carbon-based dry sorbents were injected upstream of COHPAC, downstream of the ESP over an eight week period. 


\section{SITE DESCRIPTION}

Alabama Power Company, a subsidiary of Southern Company, owns and operates the E.C. Gaston Electric Generating Plant located in Wilsonville, Alabama. The plant has four $270 \mathrm{MW}$ balanced draft and one $880 \mathrm{MW}$ forced draft coal fired boilers. All units fire a variety of lowsulfur, washed, Eastern bituminous coals.

The primary particulate control equipment on all units are hot-side ESPs. Units \#1 and \#2 and Units \#3 and \#4 share common stacks. In 1996 Alabama Power contracted with Hamon Research-Cottrell to install COHPAC downstream of the hot-side ESP on Unit 3. This COHPAC system was designed to maintain Unit \#3 and \#4's stack opacity levels below $5 \%$ on a 6 minute average ${ }^{4}$.

The COHPAC system is a pulse-jet cleaned baghouse designed to treat flue gas volumes of $1,070,000 \mathrm{acfm}$ at $290^{\circ} \mathrm{F}$ (gross air-to-cloth ratio of $8.5 \mathrm{ft} / \mathrm{min}$ with on-line cleaning). The COHPAC baghouse consists of four (4) isolatable compartments, two compartments per airpreheater identified as either A- or B-Side. Each compartment consists of two bag bundles, each having a total of 544, 23-foot long, Ryton ${ }^{\mathrm{TM}}$ felt filter bags, $18 \mathrm{oz} / \mathrm{yd}^{2}$ nominal weight. This results in a total of 1,088 bags per compartment, or 2,176 bags per casing ${ }^{4}$.

The hot-side ESP is a Research-Cottrell weighted wire design. The specific collection area (SCA) is $274 \mathrm{ft}^{2} / 1000 \mathrm{acfm}$. Depending on the operating condition of the hot-side ESP, nominally 97 to $99+\%$ of the flyash is collected in the ESP. The remaining flyash is collected in the COHPAC system. The average inlet particulate mass concentration into COHPAC between $1 / 97$ and $4 / 99$ was $0.0413 \mathrm{gr} / \mathrm{acf} \mathrm{f}^{4}$.

Hopper ash is sent to a wet ash pond for disposal. A hydrovactor system delivers the flyash to the pond.

Design parameters for Gaston Unit 3 are presented in Table 1.

\section{PROJECT OBJECTIVE AND TECHNICAL APPROACH}

The overall objective of testing at Alabama Power's Gaston Unit 3 was to determine the cost and impacts of sorbent injection into the COHPAC baghouse for mercury control. The evaluation was conducted on one-half of the gas stream, nominally $135 \mathrm{MW}$. The side chosen for testing was B-side. A-side was monitored as the control unit.

To achieve the overall objective, the program was designed with an extensive field evaluation and an equally extensive laboratory testing and analysis effort. Details of the overall test plan are presented elsewhere ${ }^{2}$. A brief description of the test plan specific to Gaston is presented herein. 
Table 1. Site Description Summary, Gaston Unit 3.

\begin{tabular}{|l|l|}
\hline Parameter Identification & Description \\
\hline Boiler Manufacturer & B\&W wall-fired \\
\hline Burner Type & B\&W XCL \\
\hline Low NOx Burners & Yes \\
\hline NOx Control (Post Combustion) & None \\
\hline Temperature (APH Outlet) & $290^{\circ} \mathrm{F}$ \\
\hline $\begin{array}{l}\text { Coal (Typical - this unit fires a } \\
\text { variety of coals) }\end{array}$ & \\
\hline \multicolumn{1}{|c|}{ Type } & Eastern Bituminous \\
\hline Heating Value (Btu/lb) & 13,744 \\
\hline Moisture (\%) & 6.9 \\
\hline Sulfur $(\%)$ & 0.9 \\
\hline Ash $(\%)$ & 13.1 \\
\hline Hg $(\mu \mathrm{g} / \mathrm{g})$ & 0.06 \\
\hline Cl $(\%)$ & 0.03 \\
\hline Control Device & \\
\hline Type & Hot-Site ESP with COHPAC \\
\hline ESP Manufacturer & Research Cottrell \\
\hline Design & Weighted Wire \\
\hline Specific Collection Area $\left(\mathrm{ft}^{2} / 1000 \mathrm{afcm}\right)$ & 274 \\
\hline Flue Gas Conditioning & None \\
\hline Baghouse Manufacturer & Hamon Research-Cottrell \\
\hline Design & Pulse-Jet, Low Pressure - High Volume \\
\hline Air-to-Cloth Ratio (acfm/ft $\left.{ }^{2}\right)$ & $8.5: 1$ (gross) \\
\hline
\end{tabular}

\section{FIELD EVALUATION}

The critical elements of the program were the actual field tests and measurements, which relied upon accurate, rapid measurements of mercury concentration and an injection system that realistically represented commercially available technology.

Near real-time vapor phase mercury measurements were made using a Semi-Continuous Emissions Monitor (S-CEM) designed and operated by Apogee Scientific. This instrument was developed with EPRI funding to facilitate EPRI research and development efforts ${ }^{5}$. The S-CEMs operated continuously for over seven weeks providing speciated, vapor phase mercury concentrations at the inlet and outlet of COHPAC.

Norit America's supplied a portable dilute phase pneumatic injection system that is typical of those used at Municipal Solid Waste (MSW) facilities for mercury control with activated carbon. ADA-ES designed the distribution and injection components of the system. 


\section{Site Specific Equipment}

Sorbent requirements for various levels of mercury control were predicted based on empirical models developed through EPRI funding ${ }^{3}$. Rates used to design equipment for the Gaston test are presented in Table 2. The system was sized for a maximum injection rate of $100 \mathrm{lbs} / \mathrm{h}$.

Table 2. Predicted Injection Rates for FGD Carbon on B-Side of COHPAC ${ }^{3}$

\begin{tabular}{|l|l|l|}
\hline $\begin{array}{l}\text { Target Hg Removal } \\
\text { Efficiency } \\
(\%)\end{array}$ & $\begin{array}{l}\text { Predicted Injection } \\
\text { Concentration } \\
\text { (lbs/MMacf) }\end{array}$ & $\begin{array}{l}\text { Predicted Injection } \\
\text { Rate }^{\mathbf{a}} \\
\text { (lbs/h) }\end{array}$ \\
\hline \hline 50 & 0.5 & $<30$ \\
\hline 75 & 1.5 & 45 \\
\hline 90 & 3.0 & 90 \\
\hline
\end{tabular}

a. Injection rate based on nominal flow at full load of 500,000 acfm.

Figure 1 is a picture of the portable injection skid supplied by Norit Americas and installed for injection into Plant Gaston Unit 3B. Activated carbon delivered to the plant in $900 \mathrm{lb}$ supersacks was loaded onto the skid by a hoist. The sorbent was metered by a variable speed screw feeder into an eductor that provided the motive force to carry the sorbent $\sim 100 \mathrm{ft}$ to the injection point.

Sorbent was carried via flexible hose from the feeder to a distribution manifold at the injection level and injected into the flue gas through six injection probes (three/duct). Figure 3 is a photograph of the distribution manifold. The injection system operated without plugging while injecting carbon based products with D50 particle size of 15 micron. The distribution system plugged once while feeding a finer material with a D50 of 6-7 microns. 
Figure 1. Carbon Injection Skid Installed at Plant Gaston

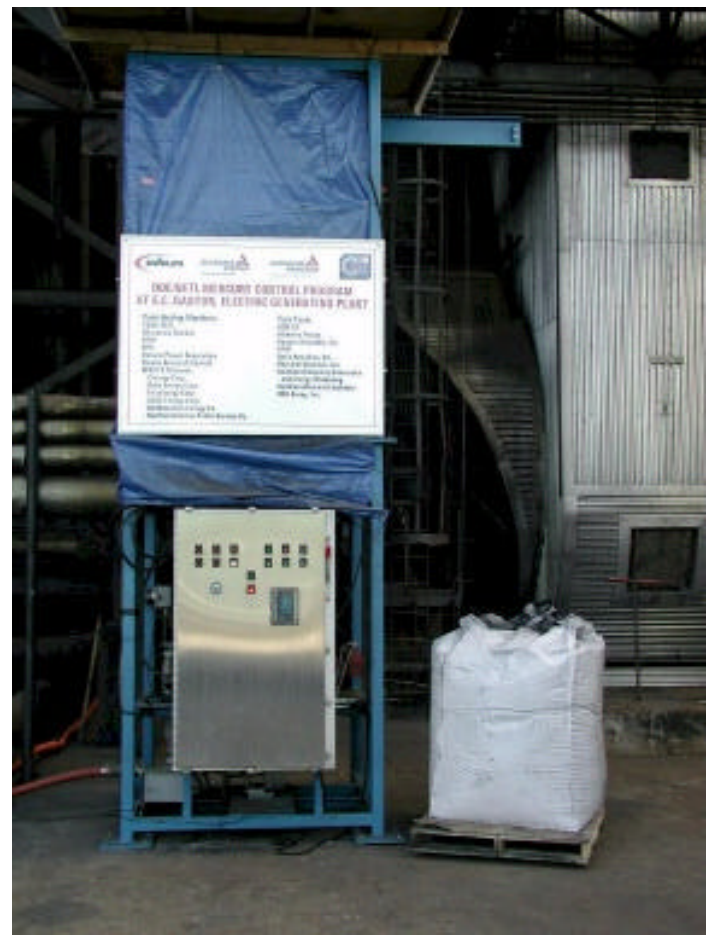

Figure 2. Distribution Manifold for Injection Lances at Plant Gaston

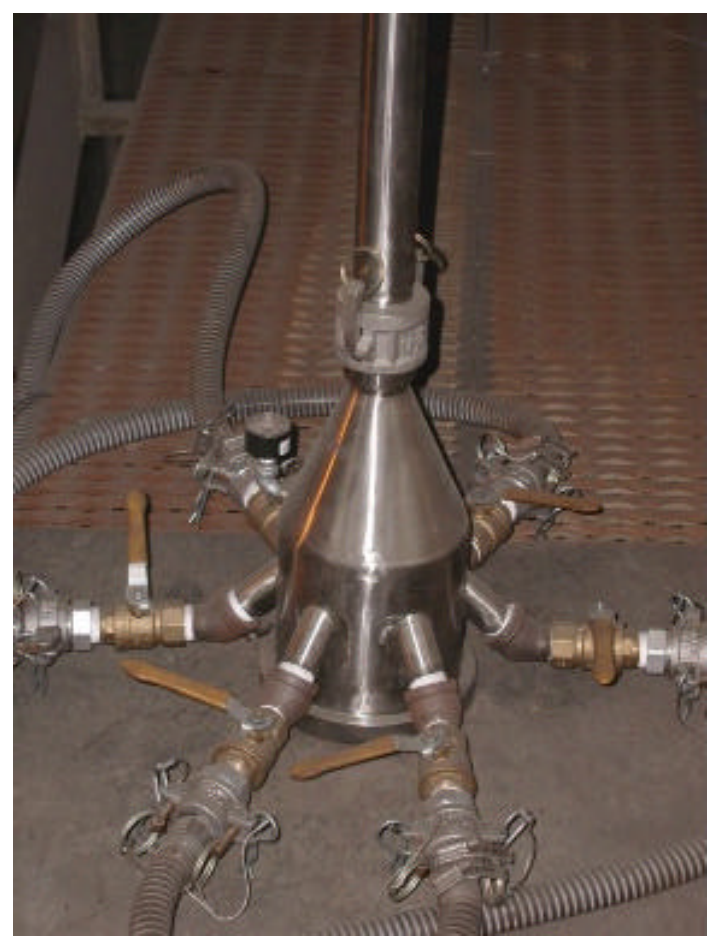




\section{Sorbent Selection}

The test plan was designed to allow for the evaluation of two sorbents during the parametric tests. The test protocol required that one of the sorbents be a lignite-derived powdered activated carbon (PAC). The second sorbent was selected based on results from fixed-bed screening tests.

Darco FGD powdered activated carbon from Norit was considered the benchmark for these tests because of its wide use in DOE/EPRI/EPA sponsored testing. Alternate sorbents were considered based on their capacity to adsorb mercury, cost and availability.

Because of the economic impact of sorbent cost on the overall cost of mercury control, it is desirable to find less expensive sorbents. The test plan included time to evaluate an alternative sorbent to Darco FGD activated carbon. This alternative sorbent could have been flyash derived, or a less expensive form of activated carbon, or a novel sorbent.

The Scope of Work supplied by DOE/NETL for this program specifically defined that only sorbents that were well along in the development and commercialization stages could be considered for testing. However, in some cases it is of interest to consider using carbon found in ash from plants within the host sites system. A sorbent selection criteria was developed so that sorbent vendors/developers could clearly understand the needs and requirements of this program. In summary an alternative sorbent must:

1. be at least 25\% less expensive than Darco FGD carbon;

2. be available in quantities of at least 15,000 lbs and 250,000 lbs for site tests;

3. show that the sorbent will be available in sufficient quantities to supply at least 100,000 tons per year by 2007 ; and

4. have a mercury adsorption capacity of at least $100 \mu \mathrm{g} / \mathrm{g}$ as measured in the laboratory by URS Corporation.

\section{Field Tests}

The field tests were separated into four different test phases:

1. Pre-baseline and Sorbent Screening;

2. Baseline;

3. Parametric; and

4. Long-Term.

\section{Pre-baseline Measurements and Screening}


The first field measurements were made prior to installing the injection equipment. The objectives for the pre-baseline tests were to:

1. Measure vapor phase mercury concentrations at several locations using the S-CEM to compare results with Ontario Hydro measurements (draft wet method used by EPA) made in 1999 (these measurements were made across the hot-side ESP on Unit1);

2. Document mercury emissions across COHPAC; and

3. Perform screening tests for mercury adsorption characteristics of several activated carbons that were candidate sorbents for the full-scale tests.

Vapor phase mercury measurements were made with the S-CEMs upstream of the hot-side ESP, upstream of the COHPAC baghouse (downstream of the hot-side ESP) and downstream of COHPAC, as shown in Figure 3. Measurements across the hot-side ESP were compared to measurements made as part of Phase III of the Information Collection Request (ICR) on Gaston Unit 1. Since no previous measurements of mercury removal across the COHPAC baghouse had been made, these tests provided important insight for planning of the actual injection tests.

Five carbon-based sorbents, three variations of ash from Gaston, and one non-carbon based sorbent were screened by URS Radian in a laboratory mercury adsorption test fixture. Six of these sorbents were then evaluated in a similar test device on a slip stream of flue gas at Gaston. A description of this screening device is presented elsewhere ${ }^{6}$.

Figure 3. Flow Schematic of Gaston Unit 3, Showing Injection and Measurement Locations

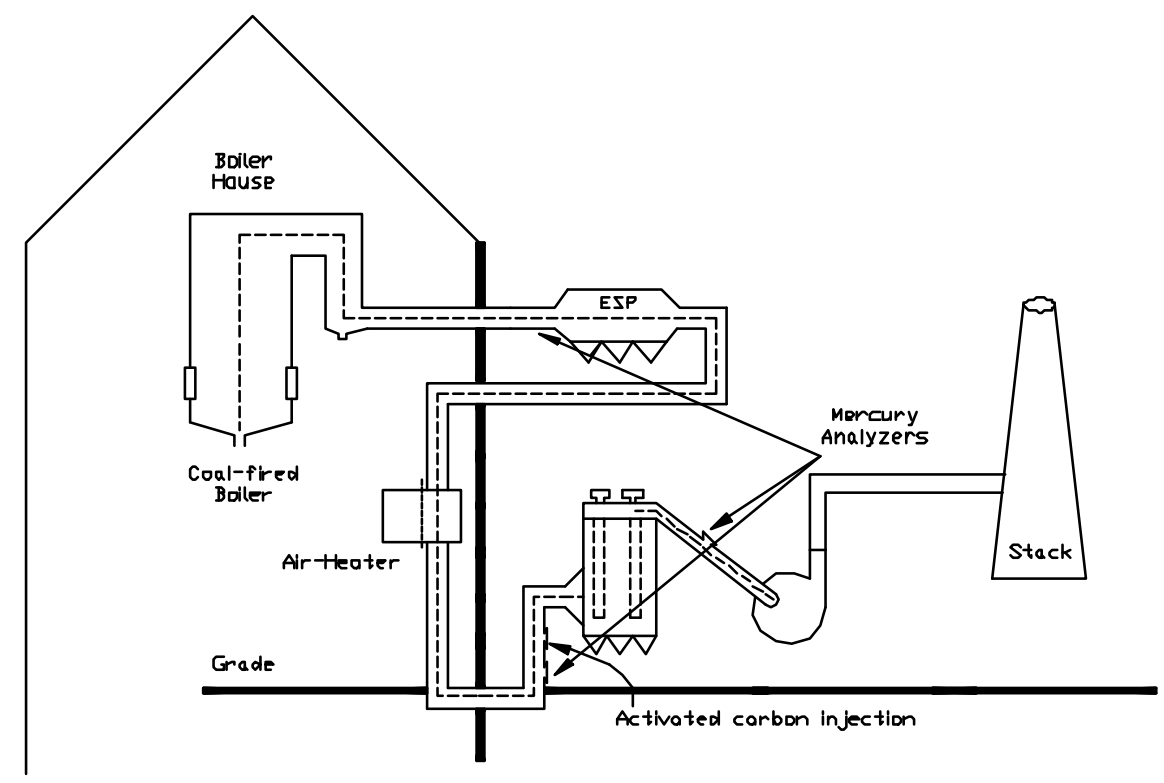




\section{Baseline Testing}

After equipment installation and checkout, a set of baseline tests were conducted immediately prior to the first parametric test series to document current operating conditions. During this test boiler load was held steady at "full-load" conditions during testing hours, nominally 7:00 am to 7:00 pm. Mercury across B-Side of COHPAC was measured using two separate methods:

1. S-CEMs; and

2. Modified Ontario Hydro Method.

In addition to monitoring mercury removal, it was also important to document the performance of COHPAC during sorbent injection which is critical to the success of sorbent injection for mercury control. The primary performance indicators are:

Pressure Drop/Drag: Pressure drop and drag are both used to monitor the permeability of the filter and dustcake. Pressure drop is a direct measurement of pressure loss across the fabric filters. Drag is a calculated number that normalizes pressure drop to flow by dividing pressure drop by the air-to-cloth ratio. These values are a function of inlet grain loading, filtering characteristics of the particulate matter, and flow and time between cleaning. Of particular interest is the change in rate of pressure drop increase with sorbent injection and whether pressure drop/drag returns to baseline levels when injection is stopped.

Cleaning Frequency: Pressure drop/drag is controlled in a baghouse by the cleaning frequency. It is expected that cleaning frequency will increase with the increased particulate loading from sorbent injection. Cleaning frequency was monitored before, during and after sorbent injection.

Opacity/Emissions : Cleaning frequency and particulate matter characteristics can affect collection efficiency across the baghouse. Most emissions occur immediately following a clean, so increasing the cleaning frequency can increase outlet emissions. The emissions could also increase if the particulate does not form a high efficiency filter cake, but tends to work through the fabrics.

Bag Strength: The filter bags in COHPAC are made from Ryton ${ }^{\mathrm{TM}}$ felt. The Ryton bags at Gaston have experienced very little loss in fabric strength, as measured by Mullen Burst tests, in the four years of operation. To assure that carbon injection will not adversely affect fabric strength, samples of both old and new bags were pulled periodically throughout the test. Prior to the baseline tests, several new bags were installed in both the A- and B- side to monitor short term strength loss.

During the baseline tests, COHPAC and plant operating data were collected. 


\section{Parametric Testing}

A series of parametric tests was conducted to determine the optimum operating conditions for several levels of mercury control up to $90 \%$ mercury removal, for several activated carbon products. To minimize permitting issues, only coal-based sorbents were considered at this site. Norit Americas lignite-based PAC, Darco FGD, was chosen as the benchmark sorbent. Darco FGD is Norit's standard product for mercury removal at MSW and incineration sites. Sorbent and injection concentration for the long term tests were chosen based on results from these tests.

In all, 15 different parametric conditions were tested. The primary variables were carbon type and target mercury removal level. Other variables included COHPAC cleaning settings and flow through the baghouse. Although lower flue gas temperatures have been correlated with increased mercury removal, temperature was not a variable during these tests because normal operating temperatures at this plant were between $250^{\circ} \mathrm{F}$ and $270^{\circ} \mathrm{F}$, which is cool enough for acceptable removal. A summary of the parametric tests is presented in Table 3. Unless noted, all tests were conducted with the boiler at full load conditions and COHPAC cleaning at a drag initiate setpoint of 0.6 inches w.c./ft/min. A description of the different carbons used in these tests is presented in Table 4 .

Table 3. Summary of Parametric Test Conditions.

\begin{tabular}{|l|l|l|l|}
\hline Test Series & Carbon Name & Target Hg Removal Efficiency (\%) & $\begin{array}{l}\text { Non Standard } \\
\text { Conditions }\end{array}$ \\
\hline $1-5$ & Darco FGD & 50,75 and 90 & Standard \\
\hline $6-9$ & Norit PAC2B & $50,75,90$ & Standard \\
\hline 10 & None & Baseline & Standard \\
\hline 11 & Darco Insul & 90 & Standard \\
\hline 12 & HydroDarco-C & 90 & Standard \\
\hline 13 a-c & Darco FGD & 75 & $\begin{array}{l}\text { Change to pressure drop } \\
\text { initiate clean }\end{array}$ \\
\hline 14 & Darco FGD & 50 & Lower A/C to 4ft/min \\
\hline 15 & Darco FGD & 50 & $\begin{array}{l}\text { Compare to test } 14 \text { with } \\
\text { A/C }=7 \mathrm{ft} / \mathrm{min}\end{array}$ \\
\hline
\end{tabular}

Table 4. Description of Norit Carbons Used in Parametric Tests.

\begin{tabular}{|l|l|l|l|l|}
\hline Name & Description & Particle Size Distribution \\
\hline \multicolumn{2}{|l|}{} & D95 & D50 & D5 \\
\hline Darco FGD & Lignite AC & 52 & $15-20$ & $<3$ \\
\hline Norit PAC2B & $\begin{array}{l}\text { Subbit/Bit Blend } \\
\text { AC }\end{array}$ & 52 & $15-20$ & $<3$ \\
\hline Darco Insul & $\begin{array}{l}\text { Fine chemically } \\
\text { washed specialty } \\
\text { product }\end{array}$ & 25 & $6-7$ & $<2$ \\
\hline HydroDarco-C & Coarser FGD & 100 & 30 & 3 \\
\hline
\end{tabular}

a. Percent of particles less than size in microns 


\section{Long-Term Performance Tests}

Long-term testing at "optimum" plant operating conditions (lowest cost/highest mercury removal), as determined from the parametric tests, were planned to gather data on:

1. Mercury removal efficiency over time;

2. The effects on COHPAC and balance of plant equipment of sorbent injection; and

3. Operation of the injection equipment to determine the viability and economics of the process.

During these tests, carbon was injected continuously 24 hours per day, for 10 days. Darco FGD activated carbon was chosen as the sorbent for these tests. Injection rate was determined taking into consideration both mercury removal and the projected increase in COHPAC cleaning frequency.

Similar to the baseline test series, mercury was measured by both the S-CEMs and manual methods (Ontario Hydro). COHPAC performance, coal and ash samples, plant CEM data were collected. During these tests an EPA audit of the manual measurements was performed.

\section{Preliminary Test Results}

Testing was concluded on April 29, 2001. At the time that this paper was written, only limited data were available, including results from S-CEMs measurements, COHPAC performance, preliminary leaching tests on COHPAC hopper ash, and coal analyses from the baseline tests.

\section{Pre-Baseline Tests}

Table 5 presents vapor phase mercury measurements during the pre-baseline tests in January. Two analyzers were used for these tests. The analyzers were set-up to measure simultaneously either across the hot-side ESP or COHPAC.

The results show that vapor phase mercury varied between 7 and $10 \mu \mathrm{g} / \mathrm{dNm}^{3}$ at all three locations. There was no measurable removal of vapor phase mercury across either the hot-side ESP or COHPAC.

These results are comparable to those made during ICR measurements on Unit 1 for total mercury concentrations and removal efficiencies. ICR measurements showed total mercury concentrations between 6.0 and $7.5 \mu \mathrm{g} / \mathrm{dNm}^{3}$ and no mercury removal across the hot-side $\mathrm{ESP}^{7}$.

It was somewhat surprising that there was no measured mercury removal across COHPAC, especially at operating temperatures below $270^{\circ} \mathrm{F}$. Review of data collected through the ICR at other plants shows that there was significant natural mercury capture on units with baghouses when firing bituminous coals ${ }^{8}$. This natural collection is assumed to occur because of exposure of the flue gas to ash on the bag dustcake. The ash at Gaston was tested for mercury adsorption capacity by URS Radian. Analysis of the ash showed high carbon content throughout the total 
size distribution and an adsorption capacity that was reasonable when compared to other ashes. However, since COHPAC is downstream of the hot-side ESP and the ESP was in excellent condition at the time of the tests, the inlet loading was very low $\left(0.04 \mathrm{gr} / \mathrm{acf}\right.$ on average ${ }^{4}$ and less than 0.01 during the tests) and there was a relatively small amount of ash present to react with mercury.

Table 5. Pre-Baseline Mercury Measurement Results (S-CEM).

\begin{tabular}{|l|l|l|}
\hline Location & \multicolumn{1}{|c|}{$\begin{array}{c}\text { Total Mercury } \\
\boldsymbol{\mu g} / \mathbf{d N m}^{\mathbf{3}} @ \mathbf{3 \%} \mathbf{O}_{\mathbf{2}}\end{array}$} & $\begin{array}{c}\text { Oxidized Mercury } \\
\mathbf{\%}\end{array}$ \\
\hline ESP Inlet & $7-10$ & $5-33$ \\
\hline ESP Outlet/COHPAC Inlet & $7-10$ & $29-51$ \\
\hline COHPAC Outlet & $7-10$ & $52-76$ \\
\hline Mercury Removal Across ESP & $0 \%$ & \\
\hline Mercury Removal Across COHPAC & $0 \%$ & \\
\hline
\end{tabular}

The portion of vapor phase mercury in the oxidized state increased in the direction of flow. There was a greater percentage of elemental mercury at the hot-side inlet (economizer outlet) than there was at either the COHPAC inlet or outlet. The most significant oxidation occurred across the COHPAC baghouse. Similar phenomena have been documented across baghouses with fiberglass fabric bags ${ }^{7}$.

Results from fixed bed screening tests on a slip stream of flue gas were similar to the laboratory results showing that the activated carbons had adsorption capacities 100 times greater than ash or a non-carbon-based sorbent. Because of the accelerated schedule at this site, it was not possible to consider either ash, or non-carbon based alternate sorbents.

\section{Baseline Tests}

Baseline testing was conducted the week of March $5^{\text {th }}$. Results from the Ontario Hydro tests were not yet available at the time this paper was written. S-CEM measurements showed vapor phase mercury varied between 8 to $12.5 \mu \mathrm{g} / \mathrm{Nm} 3$. Coal analyses showed mercury levels in the three coal samples varied between 0.06 and $0.17 \mu \mathrm{g} / \mathrm{g}$. Since Gaston burns several coals per day it is difficult to correlate a mercury level in the coal to a specific flue gas measurement.

\section{Parametric Tests}

Parametric testing showed mercury removal as a function of injection concentration and sorbent type, and the impact of sorbent injection on COHPAC performance. The parametric test conditions are presented in Table 3. Feedback from the S-CEMs were invaluable in making timely, real-time decisions on test conditions. Examples of the data provided from the S-CEMs are presented in Figure 4. These data are from the first week of parametric tests, test numbers 1 - 5, with Darco FGD. Reduction in outlet mercury concentration can be seen to correlate with relative injection rates. Actual mercury concentrations are not shown in this figure as final results have not yet been approved for release to the public. 
Results with Darco FGD showed mercury removal efficiencies as high as $90 \%$ at injection concentrations about $2.0 \mathrm{lbs} / \mathrm{Mmacf}$. This is less that the empirically predicted rate of 3.0 lbs/Mmacf ${ }^{3}$. Other carbon based products tested and described in Table 4, showed similar performance.

Carbon injection significantly increased the cleaning frequency of the COHPAC baghouse. At an injection concentration of $2.0 \mathrm{lbs} / \mathrm{Mmacf}$ the cleaning frequency increased from 0.5 to 2 pulses/bag/hour, or a factor of 4. An acceptable cleaning frequency at this site is 1.5 pulses/bag/hour, to maintain good bag life.

Figure 4. S-CEM Mercury Measurements During the First Week of Parametric Tests with Norit Darco FGD PAC

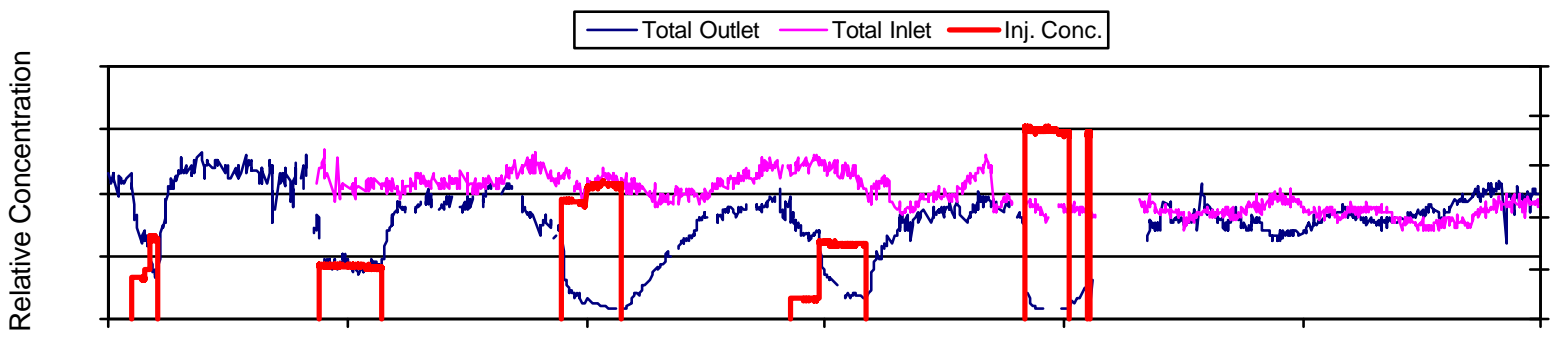

\section{Long-Term Tests}

Based on results from the parametric tests, Darco FGD was chosen as the sorbent and a target injection rate of $1.5 \mathrm{lbs} / \mathrm{Mmacf}$ was chosen to maintain COHPAC cleaning frequency below 1.5 pulses/bag/hour.

Results from the S-CEMs showed 80 - 90\% mercury removal at an injection rate of nominally $1.5 \mathrm{lbs} / \mathrm{Mmacf}$. COHPAC cleaning frequency varied between 1.0 and $1.3 \mathrm{pulses} / \mathrm{bag} / \mathrm{hour}$

\section{Coal and Ash Characterization}

Coal and ash samples were collected daily during the baseline, parametric and long-term tests. Gaston fires a variety of washed, low sulfur eastern bituminous coals. Because several coals can be fired in a day, the daily coal samples will provide relative mercury concentrations, but may not be representative of specific test periods. Standard ultimate and proximate analyses will be performed, plus measurements for mercury, chlorine, and sulfur.

Ash samples were collected from the hot-side ESP, control side (A-side) COHPAC, and test side (B-side) COHPAC hoppers.

Ash generated from the E.C. Gaston Plant is impounded using a wet ash handling system. The ash is not currently beneficially reused, therefore the waste characterization testing was aimed at assessing the stability of the mercury contained on the COHPAC collected materials. 
The standard testing technique used for assessing hazardous waste characteristics is the Toxicity Characteristic Leaching Procedure (TCLP, SW846-1311). The test protocol involves exposing a 100-gram sample of ash to 1-liter of acidic solution (acetic acid-or acetate based) for 24 hours. The solution is then analyzed for several metals (including mercury) to determine how much of each target metal was leached from the solid sample. Results are compared against limits established by regulation. In the case of mercury, a maximum leachable level of $0.2 \mathrm{mg} / \mathrm{liter}$ has been established.

A second series of tests will be performed to answer the question of the stability of the mercury. The potential long-term environmental impact of the mercury-laden ash will be determined using two techniques, leaching and thermal desorption. Leaching tests are done using a method known as the synthetic groundwater leaching procedure (SGLP) ${ }^{9}$. This test is modeled after the TCLP, but modified to allow for disposal scenarios.

Thermal desorption tests will be performed using a special test fixture that is heated using a programmable temperature controller. The temperature of the ash sample is ramped to $500{ }^{\circ} \mathrm{C}$ at a rate of $20^{\circ} \mathrm{C}$ per minute. Mercury that is released by the sample is swept to a spectrophotometer for mercury measurement as a function of time and temperature.

\section{Economic Analysis}

After completion of testing and analysis of the data, the requirements and costs for full-scale, permanent commercial implementation of the necessary equipment for mercury control using sorbent injection technology will be determined. Process equipment will be sized and designed based on test results and the plant specific requirements (reagent storage capacity, plant arrangement, retrofit issues, winterization, controls interface, etc.). A conceptual design document will be developed with drawings and equipment lists. Modifications to existing plant equipment will be determined and a work scope document developed based on input from the plant which may include modifications to the particulate collector, ash handling system, compressed air supply, electric power capacity, other plant auxiliary equipment, utilities and other balance of plant engineering requirements. Reagent type and sources will be evaluated to determine the most cost -effective reagent(s) for the site.

A cost estimate to implement the control technology will be developed. This will include capital cost estimates for mercury control process equipment as well as projected annual operating costs. Where possible, order-of-magnitude estimates will be included for plant modifications and balance of plant items. 


\section{Data Analysis and Reporting}

Data collected during the field evaluation will be used to prepare a summary report on the effect of sorbent injection on mercury control and the impact on existing pollution control equipment. Different plant signals will be monitored to determine if any correlation exists between changes in mercury concentration and measured plant operating conditions. This analysis will include a characterization of mercury levels and plant operation for baseline conditions, various injection rates, and different sorbents. This analysis will also identify effects of sorbent injection on operation and predict long term impacts.

This report shall be a stand alone document providing a comprehensive review of the testing and data analysis.

\section{CONCLUSIONS}

A comprehensive evaluation of mercury control using activated carbon injection upstream of a COHPAC baghouse was conducted at Alabama Power Company's Plant Gaston Unit 3. Final results were not available at the time that this paper was due; however, preliminary results and trends were encouraging.

- Effective mercury removal, up to $90 \%$ efficiency, was obtained with Darco FGD powdered activated carbon.

- A significant increase in the cleaning frequency of the COHPAC baghouse occurred with the injection of activated carbons. At this site, the maximum acceptable cleaning frequency and pressure drop limited the amount of sorbent that could be injected.

- Actual and theoretical removals were in reasonably close agreement for 80 to $90 \%$ removal (1.5 to 2 vs $3 \mathrm{lbs} / \mathrm{Mmacf}$ ) considering that the model is based on a uniform particle size of 15 microns while the actual FGD carbon used has a wide size distribution with significant numbers below 15 microns.

- Using data obtained from these tests, future COHPAC (TOXECON) baghouses can be designed to operate acceptably with carbon injection.

\section{REFERENCES}

1. Brown, T.D., D.N. Smith, R.A. Hargis and W.J. O'Dowd. "Mercury Measurement and Its Control: What We Know, Have Learned, and Need to Further Investigate," J. Air \& Waste Management Association, pp. 1-97, June 1999.

2. Durham, M.D, C.J. Bustard, R. Schlager, C. Martin, S. Johnson, S. Renninger. “Field Test Program to Develop Comprehensive Design, Operating and Cost Data for Mercury Control Systems on N-on Scrubbed Coal-Fired Boilers". Presented at the Air \& Waste Management Association 2001 Annual Conference and Exhibition, June 24-28, 2001, Orlando, FL.

3. Meserole, F.B., R. Chang, T.R. Carey, J. Machac, and C.F. Richardson, "Modeling Mercury Removal by Sorbent Injection,” J. Air \& Waste Mange. Assoc., 49, 694-704, 1999. 
4. Miller, Richard, W. Harrison, B. Corina, K. Cushing, R. Chang. "COHPAC (Compact Hybrid Particulate Collector) The Next Generation in Particulate Control Technology Alabama Power Company's E. C. Gaston Units \#2 and \#3 “A Success Story". Presented at the EPRI-DOE-EPA Combined Utility Air Pollution Control Symposium: The MEGA Symposium, Atlanta Georgia, August 16 - 20, 1999.

5. Bustard, C. Jean, M. Durham, Ph.D., S. Johnson, S. Sjostrom, R. Slye, S. Renninger, R. Afonso, C. Senior, H. Stowe. "Understanding and Enhancing the Effects of $\mathrm{NO}_{\mathrm{x}}$-Control Systems on Hg Emissions at Salem Harbor Unit \#3." Presented at the "A\&WMA Specialty Conference on Mercury Emissions: Fate, Effects and Control," Chicago, IL, August 21 -23, 2001.

6. Laboratory Investigations and Model Development of Flue Gas Mercury Adsorption Using Solid Sorbents," EPRI Report TR-110533, EPRI, Palo Alto, CA, 1998.

7. EPA website, http://www.epa.gov/ttn/atw/combust/utiltox/utoxpg.html.

8. Sjostrom, S.M., J. Bustard, M. Durham Ph.D., R. Chang Ph.D. "Mercury Removal Trends in Full-Scale ESPs and Fabric Filters". Presented at the "A\&WMA Specialty Conference on Mercury Emissions: Fate, Effects and Control,” Chicago, IL, August 21 -23, 2001.

9. Hassett, D.J., D.F. Pflughoeft-Hassett, D.L. Laudal and J.H. Pavlish. "Mercury Release from Coal-Combustion By-Products to the Environment," Mercury in the Environment Specialty Conference, Minneapolis, MN, September 15-17, 1999. 


\section{Fin}

\section{CONTROLLING MERCURY EMISSIONS FROM COAL-FIRED UTILITY BOILERS:}

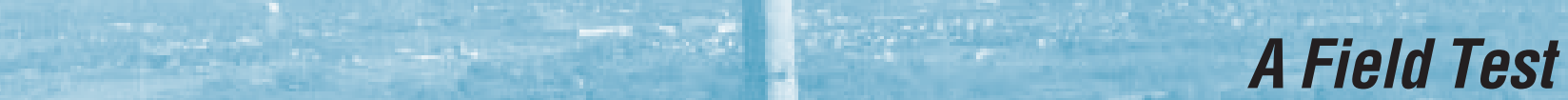

by Michael D. Durham, C. Jean Bustard, Richard Schlager, Cameron Martin, Stephen Johnson, and Scott Renninger

This article is based on a presentation given at A\&WMA's $94^{\text {th }}$ Annual Conference \& Exhibition in June in Orlando, FL. It describes a comprehensive multisite test program to demonstrate mercury control at four full-scale power plants. Tests results from three of these sites will be presented for the first time at A\&WMA's Specialty Conference on Mercury, "Mercury Emissions: Fate, Effects, and Control," which will be held at the Arlington Heights Sheraton in Chicago, IL, August 21-23, 2001. For more details on the conference, see $\mathrm{p} 33$.

The following article describes a field test program being conducted by ADA-ES that represents EPA's first step toward defining technology to be used by power-generating companies in meeting new mercury regulations.

The company is working in partnership with several organizations to design and engineer systems to maximize effectiveness and minimize costs in order to reduce mercury emissions from coal-fired utility boilers.

\section{INTRODUCTION}

On December 14, 2000, the U.S. Environmental Protection Agency (EPA) announced that it plans to develop regulations to reduce mercury emissions from coal-fired utility boilers (see "EPA Studies on the Control of Toxic Air Pollution Emissions from Electric Utility Boilers," EM, January 2001, pp 30-36). This decision is based on growing concerns of adverse health effects due to current levels and potential buildups of methylmercury in lakes and rivers. Methylmercury is capable of bioaccumulation, resulting in higher levels being found in game fish. Mercury is a neurotoxin that impacts rapidly developing cells; people at greatest risk of exposure are pregnant women who consume fish with elevated levels of mercury. 
The levels currently being found in lakes in several areas of the country are sufficiently high that state health agencies are issuing advisories to restrict fish consumption. Over the past 10 years, much effort has been directed toward reducing the use of mercury in consumer products. In addition, new emission control technologies have been implemented on medical waste and municipal waste incinerators. As a result, coal-fired electric generators now represent the largest single source of anthropogenic mercury emissions in the United States.

In anticipation of potential regulations, considerable research has been conducted during the past decade to characterize the emissions and control of mercury compounds from coal combustion. The U.S. Department of Energy (DOE), EPA, and the Electric Power Research Institute (EPRI) funded much of this research. These research efforts are summarized in A\&WMA's 1999 Critical Review, entitled "Mercury Measurement and Its Control: What We Know, Have Learned, and Need to Further Investigate." 1

\section{PROGRAM OBJECTIVES}

With stricter regulations imminent, it is important to concentrate the development effort on the most mature control technologies. Injection of dry sorbents (e.g., such as activated carbon) into the flue gas and further collection of the sorbent by conventional particulate control devices, such as electrostatic precipitators (ESPs) and fabric filters, represents the most mature and potentially most cost-effective control technology for power companies. However, work has been limited to bench-scale and pilot experiments., ${ }^{2,3}$ Although these reducedscale programs provide valuable insight into many important issues, they cannot fully account for impacts of additional control technology on plantwide equipment. For example, it has been possible to measure high mercury capture at relatively low temperatures in small pilot systems for relatively short periods. However, these lower temperatures may not be practical in a full-scale system continuously without deposition and corrosion in cold spots of ducting and particulate control equipment. Therefore, it is necessary to perform full-scale field tests to document actual performance levels and determine accurate cost information. The objectives of this field test program are to

- $\quad$ accelerate the availability of commercial mercury control systems for coal-fired plants;

- obtain data on the control systems'operability, maintainability, and reliability;

- determine maximum mercury removal for various plant configurations; and

- determine the total costs associated with mercury control as a function of fuel and plant characteristics.

The program is intended to provide critical data that will be used by many different groups: It will provide EPA with accurate information on the levels of control that can be reasonably attained for different plants; it will complement the emission inventory data obtained during the 1999 EPA Information Collection Request (ICR) data collection effort; and it will provide power-generating companies with the means to estimate costs to perform strategic planning on a systemwide basis. The economic analysis will include capital costs; sorbent usage costs; impact on operation of particulate control equipment; balance of plant; waste disposal and byproduct utilization issues; enhancements, such as cooling; and operation and maintenance $(\mathrm{O} \& \mathrm{M})$ requirements.

ADA Environmental Solutions (ADA-ES) has assembled a program team consisting of technical leaders in the areas of mercury measurement, transformation during coal combustion, capture by existing emission control equipment, and design of integrated emission control systems. The qualifications of individual team members were determined by their contribution to pioneering mercury control work in the United States over the past decade. Organizations represented on the team include URS Radian, Inc.; Physical Sciences, Inc.; Apogee Scientific; EPRI; Energy \& Environmental Strategies; EnviroCare; Microbeam Technologies; Energy and Environmental Research Center (EERC); Environmental Elements Corp.; Consol Energy, Inc.; Hamon Research Cottrell; and NORIT Americas.

\section{TEST SITES}

The program is directed at providing sufficient data to determine costs and capabilities for plants that do not have flue gas desulfurization (FGD) systems. This group represents not only the largest proportion of coal-fired power generators ( $83 \%$ by number or $75 \%$ by generation capacity), but it also represents the most difficult application for mercury control. To gather data on the application of sorbent injection for removal of mercury from coal combustion flue gas that can be used for as many plants as possible, sites were selected to take into account factors related to the fuel characteristics, the operating conditions of the unit, and interactions with other air pollution control devices. Sites that burn both eastern bituminous and western subbituminous coals were included because of differences in speciation of mercury in the flue gas, which greatly affects the efficiency of mercury removal in air pollution control devices. Measurements of the concentration of mercury species taken in the stacks of pilot and full-scale coal combustion systems reported anywhere from $10 \%$ to $95 \% \mathrm{Hg}^{0}$ upstream of the air pollution control device. ${ }^{1}$ Oxidized mercury, particularly when present as $\mathrm{HgCl}_{2}$, is far easier to capture than is mercury in elemental $\left(\mathrm{Hg}^{0}\right)$ form.

In addition to differences in the forms of mercury produced by different coals, the fly ash produced by bituminous and subbituminous coals result in different mercury capture characteristics. 
Table 1. Mercury emissions data from three of the host sites.

\begin{tabular}{l|c|c|c|c}
\hline $\begin{array}{l}\text { Plant and Unit } \\
\text { Sampling Location }\end{array}$ & Particle Bound & Oxidized Hg & \\
\hline Brayton Point U3 & Elemental Hg & Total Hg \\
Inlet $(\mu \mathrm{g} / \mathrm{dscm})$ & 1.58 & 2.53 & $<1.18$ & 5.3 \\
Outlet $(\mu \mathrm{g} / \mathrm{dscm})$ & 0.39 & 2.09 & $<1.19$ & 3.67 \\
Removal efficiency (\%) & 76.46 & 16.93 & -3.25 & 31.92 \\
\hline Salem Harbor U3 & & & & \\
Inlet $(\mu \mathrm{g} / \mathrm{dscm})$ & 2.83 & 0.10 & 0.29 & 3.22 \\
Outlet $(\mu \mathrm{g} / \mathrm{dscm})$ & 0.0554 & 0.0925 & 0.2501 & 0.3980 \\
Removal efficiency (\%) & 97.96 & -23.07 & 8.62 & 87.28 \\
\hline Gaston U1 & & & & 6.80 \\
Inlet $(\mu \mathrm{g} / \mathrm{dscm})$ & 2.26 & 1.72 & 2.81 & 6.65 \\
Outlet $(\mu \mathrm{g} / \mathrm{dscm})$ & 0.60 & 3.99 & 2.06 & 2.21 \\
Removal efficiency (\%) & 73.45 & -131.98 & 26.69 & \\
\hline \hline
\end{tabular}

aMeasurements made across hot-side ESP not COHPAC baghouse.

For example, subbituminous ashes produce higher absorption rates of mercury at higher temperatures and lower levels of carbon than do ashes from bituminous coals. There are other important differences between the flue gas produced by eastern and western coals. For eastern bituminous coals, a small proportion ( $2 \%$ to $3 \%$ ) of the sulfur dioxide $\left(\mathrm{SO}_{2}\right)$ is converted to sulfur trioxide $\left(\mathrm{SO}_{3}\right) \cdot \mathrm{SO}_{3}$ is important because it reacts with the water vapor to form sulfuric acid. The gas stream for a low-sulfur eastern coal will have sufficient $\mathrm{SO}_{3}$ that sulfuric acid will begin to condense at $270{ }^{\circ} \mathrm{F}$. This means that the gas stream cannot be cooled for enhancement of mercury capture without first eliminating the $\mathrm{SO}_{3}$, or else severe corrosion of ducting and ESP components would be expected. On the other hand, the higher alkali content of a western subbituminous coal neutralizes all of the $\mathrm{SO}_{3}$, resulting in a dew point of $120^{\circ} \mathrm{F}$. This means that a flue gas cooling system could be operated without sulfuric acid corrosion. If an $\mathrm{SO}_{3}$ injection system is used to control particle resistivity in the ESP, its operation must be integrated with the gas cooling system to provide both resistivity and control without causing corrosion problems.
$10 \%$ of the current power plant applications, they are an important part of the program because the number of fabric filters could increase significantly as a result of stricter mercury control regulations. If a high level of mercury removal is mandated, a baghouse may be the most economical choice. Meserole 4 predicts that achieving $80 \%$ mercury removal at a plant with an ESP would require 10 times the amount of sorbent as would be required if a fabric filter were installed. The difference in the cost of the additional sorbent would be greater than the annualized cost of a new fabric filter. In addition, a number of power plants use ESPs with small specific collection areas (SCAs) that would have difficulty dealing with the additional loading of the difficult-to-collect carbon sorbent.

As a result, we decided to include a COHPAC baghouse in the test program, a cost-effective retrofit option for power plants with ESPs. COHPAC, EPRI's patented Compact Hybrid Particulate Collector concept, places a high air-to-cloth ratio baghouse downstream of an existing ESP to improve overall particulate collection efficiency.
Dry sorbents can be injected upstream of the COHPAC and downstream of the ESP. There are three main advantages to this configuration:

1. sorbents are mixed with a small fraction of the ash (nominally $1 \%)$, which reduces the impact on ash reuse and waste disposal;

2. sorbent requirements are reduced by a factor of 10 relative to the existing ESP; and

3. capital costs for COHPAC are less than other options, such as replacing the ESP with a baghouse or installing a larger ESP.

Four power plants are participating in the field test program: Alabama Power Co.'s Gaston facility; Wisconsin Electric Power Co.'s Pleasant Prairie facility; and PG\&E National Energy Group's Salem Harbor and Brayton Point facilities. These four plants provide a means to document the performance of mercury control technology 
for both subbituminous Powder River Basin (PRB) coals and low-sulfur bituminous coals. Three of the plants have ESPs, while the fourth plant has both a hot-side ESP and a COHPAC baghouse. Table 1 presents data on mercury emissions from three of the four plants as determined during the ICR testing. Additional details on the four plants are provided below.

Alabama Power's Gaston Unit 3 is a $270 \mathrm{MW}$ B\&W wallfired boiler that burns a washed Alabama bituminous coal. The coal has a heating value of $13,700 \mathrm{BTU} / \mathrm{lb}$, with a mercury content of $0.06 \mu \mathrm{g} / \mathrm{g}$ and $0.03 \%$ chlorine. Particulate is captured by a Hamon Research Cottrell hot-side weighted-wire ESP with an SCA of $274 \mathrm{ft}^{2} / \mathrm{kacfm}$. A Hamon Research Cottrell COHPAC baghouse is used with an air-to-cloth ratio of 8.5:1 gross; the temperature of the baghouse ranges from 240 to $300{ }^{\circ} \mathrm{F}$. During the test program, the sorbent will be injected downstream of the ESP and air preheater and upstream of the baghouse. This test program was conducted during spring 2001.

Wisconsin Electric's Pleasant Prairie Unit 2 is a $600 \mathrm{MW}$ Riley Stoker balanced-draft, turbo-fired boiler that burns PRB coal. The coal has a heating value of $11,897 \mathrm{BTU} / \mathrm{lb}$, with $0.1 \mu \mathrm{g} / \mathrm{g}$ mercury and $0.0015 \%$ chlorine. Particulate is captured by a Hamon Research Cottrell cold-side weighted-wire ESP with an SCA of $468 \mathrm{ft}^{2} / \mathrm{kacfm}$. A Wahlco $\mathrm{SO}_{3}$ system is used to condition the fly ash. The unit operates in a temperature range of 280 to $310^{\circ} \mathrm{F}$. Mercury control testing will be conducted during September and October 2001.

PG\&E's Salem Harbor Unit 1 is an 85 MW B\&W radiant boiler that fires a South American bituminous coal. The coal has a heating value of $11,300 \mathrm{BTU} / \mathrm{lb}$, with $0.03 \mu \mathrm{g} / \mathrm{g}$ mercury and $0.03 \%$ chlorine. Particulate is captured by an Environmental Elements cold-side rigid-electrode ESP with an SCA of $474 \mathrm{ft}^{2} / \mathrm{kacfm}$. A FuelTech urea-based selective noncatalytic reduction system is used to control levels of nitrogen oxides $\left(\mathrm{NO}_{\mathrm{x}}\right)$. The ESP operates at temperatures as low as $250^{\circ} \mathrm{F}$. Tests were scheduled to be completed in spring 2001.

PG\&E's Brayton Point is a 122 MW CE tangential, twinfurnace boiler burning a low-sulfur eastern bituminous coal. The coal has a heating value of $12,319 \mathrm{BTU} / \mathrm{lb}$, with $0.05 \mu \mathrm{g} / \mathrm{g}$ mercury and $0.08 \%$ chlorine. A pair of ESPs is used in series to capture particulate: a Koppers weighted-wire cold-side ESP with an SCA of $156 \mathrm{ft}^{2} / \mathrm{kacfm}$ and a Hamon Research Cottrell rigid-electrode ESP with an SCA of $403 \mathrm{ft} 2 / \mathrm{kacfm}$. An EPRICON SO$~_{3}$ system is used to condition the fly ash. The plant uses Separations Technology equipment to process the collected fly ash by electrostatically separating carbon from the fly ash. ${ }^{5}$ These tests are scheduled for fall 2002.

\section{SORBENT SELECTION AND SCREENING}

The test program at each site allows for the evaluation of two sorbents: a lignite-derived activated carbon supplied by NORIT (referred to as Darco FGD carbon) and one alternative sorbent. FGD is considered the benchmark for these tests because of its wide use in DOE/EPRI/EPA-sponsored testing. Because of the economic impact of sorbent costs on the overall cost of mercury control, it is desirable to find either less expensive sorbents, such as fly ash-derived products, or a less expensive form of activated carbon. Sorbent selection criteria have been developed so that sorbent vendors/developers can clearly understand the needs and requirements of this program. In summary, an alternative sorbent must be

- at least 25\% less expensive than FGD carbon;

- available in quantities of at least 15,000 lbs (and potentially as high as $250,000 \mathrm{lbs}$ ) for site tests;

- available in sufficient quantities to supply at least 100,000 tons per year by 2007 ; and

- demonstrate a capacity for mercury capture of at least $100 \mu \mathrm{g} / \mathrm{g}$ as measured by URS.

Sorbents will be tested on a slipstream of flue gas for sitespecific mercury capacity using URS' fixed-bed mercury absorption device. This device was developed with funding from EPRI and has been used to screen dozens of sorbents. Adsorption tests are conducted by saturating sorbents with either elemental mercury or mercuric chloride in the presence of simulated flue gas. The test apparatus is illustrated in Figure 1. In the laboratory, simulated flue gas is prepared by mixing heated nitrogen gas streams containing $\mathrm{SO}_{2}$, hydrochloric acid $(\mathrm{HCl}), \mathrm{NO}_{x}$, carbon dioxide, water, and ozone. Mercury is injected into the gas by contacting nitrogen carrier gas with either recrystallized mercuric chloride solids or an elemental mercury permeation tube housed in a mercury diffusion vessel; mercury concentration is controlled by the temperature of the diffusion vessel and the nitrogen carrier gas flow rate. During field tests, actual flue gas is drawn into the apparatus.

The amount of mercury exiting the sorbent column is measured on a semi-continuous basis. Gas is passed through the column until $100 \%$ of the inlet mercury is detected at the outlet (100\% breakthrough). The 100\% breakthrough (equilibrium) capacity of the sorbent ( $\mu \mathrm{g} \mathrm{Hg} / \mathrm{g}$ sorbent) is determined by summing the total mercury adsorbed until the outlet mercury concentration is first equal to the inlet concentration.

\section{SEMI-CONTINUOUS EMISSIONS MONITOR}

Semi-continuous gaseous mercury analyzers built by Apogee Scientific will be used during this program to provide near real-time feedback during baseline, parametric, and long-term testing. Continuous measurement of mercury at the inlet and outlet of the particulate collector, where mercury levels fluctuate with boiler operation (temperature, load) and decisions must be made concerning parameters such as sorbent feedrate and cooling, is considered a critical component of a field mercury control program. The analyzers that will be used for this program consist of a commercially available cold vapor atomic absorption spectrometer (CVAAS) coupled with a 


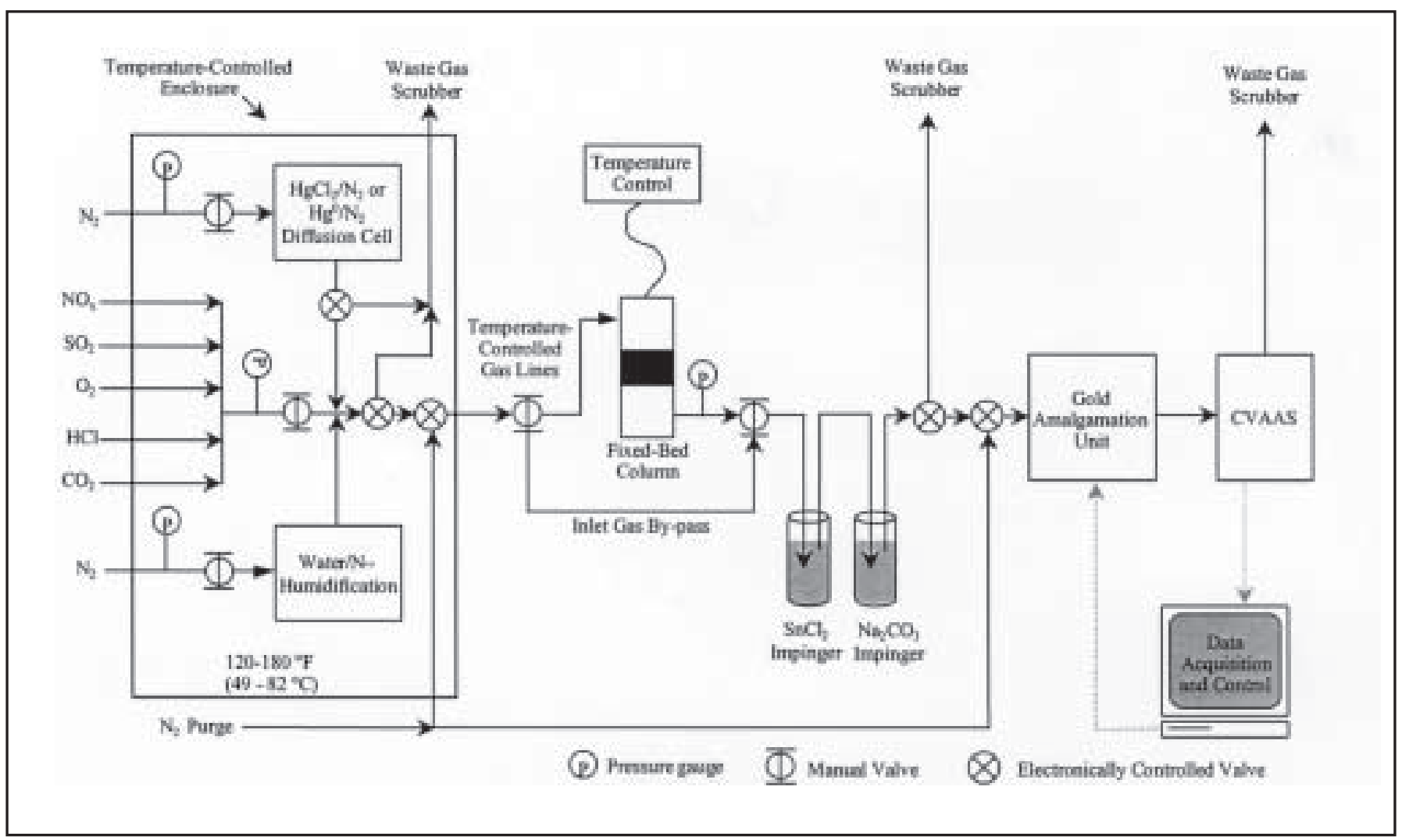

Figure 1. Bench-scale, fixed-bed mercury adsorption system.

gold amalgamation system (Au-CVAAS). One analyzer will be placed at the inlet and one at the outlet of the particulate collector during this test program.

Although it is very difficult to transport nonelemental mercury in sampling lines, elemental mercury can be transported without significant problems. Since the Au-CVAAS measures mercury by using the distinct lines of ultraviolet absorption characteristic of elemental $\mathrm{Hg}^{0}$, the nonelemental fraction is either converted to elemental mercury (for total mercury measurement) or removed (for measurement of the elemental fraction) near the sample extraction point. This minimizes any losses due to the sampling system. For total vapor-phase mercury measurements, all nonelemental vapor-phase mercury in the flue gas must be converted to elemental mercury. A reduction solution of stannous chloride in $\mathrm{HCl}$ is used to convert $\mathrm{Hg}^{2+}$ to $\mathrm{Hg}^{0}$. The solution is mixed as prescribed in the draft Ontario Hydro Method for manual mercury measurements. ${ }^{6}$

To measure speciated mercury, an impinger of potassium chloride solution mixed as prescribed by the draft Ontario Hydro Method is placed upstream of the stannous chloride solution to capture oxidized mercury. Unique to this instrument is the ability to continuously refresh the impinger solutions to assure continuous exposure of the gas to active chemicals. The Au-CVAAS system is calibrated using elemental mercury vapor, by injecting a metered volume of mercury-laden air from the air space of a vial containing liquid mercury at a precisely measured temperature into the analyzer.
The Au-CVAAS can measure mercury over a wide range of concentrations. Since the detection limit of the analyzer is a function of only the quantity of mercury on the gold wire and not the concentration in the gas, the sampling time can be adjusted for different situations. Laboratory tests with stable permeation tube mercury sources and standard mercury solutions indicate that the noise level for this analyzer is $0.2 \mathrm{ng}$ mercury. To sample at 50 to 100 times the noise level during field testing, the sampling time is set so at least 10 ng mercury is collected before desorption. For example, if the mercury concentration is $5 \mu \mathrm{g} / \mathrm{m}^{3}$, a one-minute sample time would be required, where as for a concentration of $0.5 \mu \mathrm{g} / \mathrm{m}^{3}, 10 \mathrm{~min}$ utes of sample time would be required.

Particulate is separated from the gas sample using a self-cleaning inertial gas separation arrangement modified for use with this mercury analyzer under an EPRI mercury control program. This arrangement uses a system where excess sample flow continuously scours particulate from a secondary filter so as to minimize any mercury removal or conversion due to the presence of particulate.

\section{SORBENT INJECTION EQUIPMENT}

The sorbent injection equipment is a skid-mounted, portable, dilute-phase pneumatic system. The activated carbon will be delivered to the plant in 900-lb supersacks, which will be stored on pallets adjacent to the injection skid. The reagent is metered by a variable-speed, screw feeder into an eductor that provides the motive force to carry the reagent to the 
injection point. A positive displacement blower provides the conveying air. A programmable logic controller is used to control system operation and adjust injection rates. Flexible hoses will carry the reagent from the feeder to a distribution manifold located upstream of the particulate collector feeding multiple injection probes inserted into the duct to distribute the sorbent evenly across the flue gas.

\section{FIELD TESTING}

Prior to installing injection equipment, preliminary system operation, performance, and mercury-level measurements will be made. Mercury will be measured using a semi-continuous emissions monitor (S-CEM) across the particulate control device, which will be run continuously for a minimum of 24 hours at each site. These measurements will be used to expedite the parametric evaluation and provide insight as to current mercury removal efficiencies during "normal" operation with varying boiler load. These data will be used to design the parametric tests with the minimum number of uncontrolled variables.

After installation of the sorbent injection equipment, a second set of baseline tests will be conducted to fully document baseline conditions. During this test, boiler load will be held steady at "fullload" conditions during testing hours (7:00 a.m. to 7:00 p.m.). Mercury levels across the particulate control device will be measured using two separate methods: the S-CEM and standard Ontario Hydro Testing. This baseline test is expected to run for one week.

Following the baseline test, a parametric series of tests will be conducted to document mercury removal levels as a function of injection rate and gas temperature. The flue gas temperature will be lowered at each condition to document the effect of a 10 to $20^{\circ} \mathrm{F}$ decrease in temperature on mercury removal efficiencies. The maximum sorbent injection rate will be established using either a 90\% mercury removal level or a sorbent feed proportional to $30 \mathrm{lb} /$ Macf, which is considered an economic maximum.

The next series of parametric tests will be conducted using an alternative sorbent. Mercury removal as a function of injection rate will be measured at the optimum temperature measured during the previous test series. After this test the field crew will analyze the data and work with team members on establishing conditions for the long-term test. The final test will be a mercury removal validation program conducted for a maximum of 14 days at the "optimum" plant operating conditions (lowest cost/highest mercury removal) as determined from the parametric tests. The S-CEM will be used for continuous monitoring of mercury removal. Ontario Hydro measurements will be conducted at the inlet and outlet.

During each field test program, samples of the ash/sorbent mixture from the hoppers will be collected and analyzed. The standard testing technique used for assessing hazardous waste characteristics is the Toxicity Characteristic Leaching Procedure (TCLP). A 100-g sample of ash is exposed to 1 liter of acidic solution (acetic acid- or acetate-based) for 24 hours. The solution is then analyzed for several metals (including mercury) to determine how much of each target metal was leached from the solid sample. Results are compared against limits established by regulation. In the case of mercury, a maximum leachable level of $0.2 \mu \mathrm{g} / \mathrm{liter}$ has been established.

A second series of tests will be performed by EERC to answer the question of the stability of the mercury. The potential longterm environmental impact of the mercury-laden ash will be determined using two techniques: leaching and thermal desorption. Leaching tests are done using a method known as the synthetic groundwater leaching procedure (SGLP). ${ }^{7}$ This test is modeled after the TCLP, but modified to allow for disposal scenarios. A shake-extraction technique is used to mix the solid sample with an aqueous solution; aliquots of the liquid are analyzed after 18 hours, two weeks, and four weeks. Thermal desorption tests will be performed using a special test fixture that is heated using a programmable temperature controller. The temperature of the ash sample is ramped to $500{ }^{\circ} \mathrm{C}$ at a rate of $20^{\circ} \mathrm{C}$ per minute. Mercury that is released by the sample is swept into a spectrophotometer for mercury measurement as a function of time and temperature.

After completion of testing and analysis of the field data, the requirements and costs for full-scale, permanent commercial implementation of the necessary equipment for mercury control using sorbent injection technology will be determined. The following need to be considered: the size and design of process equipment, based on test results and plant-specific requirements (reagent storage capacity, plant arrangement, retrofit issues, winterization, controls interface); modifications to existing plant equipment, including the particulate collector, ash handling system, compressed air supply, electric power capacity, other plant auxiliary equipment, utilities, and other balance of plant engineering requirements; and type and source of reagent to determine the most cost-effective reagent(s) for the site. 


\section{TECHNOLOGY TRANSFER}

Transferring the information generated during this field test program to the coal-fired power-generation industry will be an important part of the program. This will be accomplished through technical papers presented at various forums, including A\&WMA's Annual Conference and Specialty Conference on mercury, Institute for Clean Air Companies (ICAC) meetings, and the EPRI/ DOE/EPA Mega Symposium (see opposite). In addition, results from the test programs will be made available to the public via the ADA-ES Web site, $w w w$.adaes.com as soon as DOE approves them.

\section{ACKNOWLEDGEMENTS}

Such a large-scale field test program could not be conducted without technical and administrative support from a large number of people at the various power-generating companies. The authors would like to acknowledge all of these individuals and especially the following key personnel: Dr. Larry Monroe, Southern Company Services; Herb Stowe, PG\&E; and Dick Johnson, Wisconsin Electric. Also, the authors acknowledge the valuable input provided by Dr. Ramsay Chang, EPRI, and James Kilgroe, EPA.

\section{REFERENCES}

1. Brown, T.D.; Smith, D.N.; Hargis, R.A.; O'Dowd, W.J. Mercury Measurement and Its Control: What We Know, Have Learned, and Need to Further Investigate; J. Air \& Waste Manage. Assoc. 1999, 49, 628-640.

2. Haythornthwaite, S.; Sjostrom, S.; Ebner, T.; Ruhl, J.; Slye, R.; Smith, J.; Hunt, T.; Chang, R.; Brown, T. Performance of Activated Carbon for Mercury Control in Utility Flue Gas Using Sorbent Injection. Presented at the EPRI-DOE-EPA Combined Utility Air Pollutant Control Symposium, Washington, DC, August 1997.

3. Sjostrom, S.; Smith, J.; Chang, R.; Brown, T. Demonstration of Dry Carbon-Based Sorbent Injection for Mercury Control in Utility ESPs and Baghouses. Presented at the 90th Annual Meeting \& Exhibition of A\&WMA, Toronto, Ontario, June 1997.

4. Meserole, F.B.; Chang, R.; Carey, T.R.; Richardson, C.F. Estimating Electric Utility Mercury Control Costs using Sorbent Injection. Presented at the EPRI-DOE-EPA Combined Utility Air Pollutant Control Symposium, Atlanta, GA, August 1999.

5. Gasiorowski, S., Bittner, J., Willauer, C., and Vasiliauskas, A. Reliability and Quality through Processing: Beneficiation of High LOI Fly Ash for Concrete. Presented at the 1998 Conference on Unburned Carbon on Utility Fly Ash, Pittsburgh, PA, May 1998.

6. American Society for Testing and Materials. Standard Test Method for Elemental, Oxidized, Particle-Bound, and Total Mercury in Flue Gas Generated from Coal-Fired Stationary Sources (Ontario Hydro Method); ASTM draft method; American Society for Testing and Materials, October 1999.

7. Hassett, D.J.; Pflughoeft-Hassett, D.F.; Laudal, D.L.; Pavlish, J.H. Mercury Release from Coal-Combustion By-Products to the Environment. Presented at the Mercury in the Environment Specialty Conference, Minneapolis, MN, September 1999.

\footnotetext{
About the Authors

Michael D. Durham, Ph.D., president, C. Jean Bustard, executive vice president, Richard Schlager, vice president of research and development, and Cameron Martin, engineering manager, all work for ADA Environmental Solutions (ADA-ES) in Littleton, CO. Stephen Johnson is vice president of eastern operations for ADA-ES in Londonderry, NH. ADA-ES is an environmental technology and specialty chemicals company that provides power generators and industrial companies with proprietary products and systems that help them mitigate any negative impact on the environment while also reducing their operating costs.

Scott Renninger is a program manager for the U.S. Department of Energy's National Energy Technology Laboratory in Morgantown, WW.
} 